\title{
Gaming for Good Changing the Game for Corporate Sustainability
}

\author{
Petteri Alinikula, Juha-Lasse Latikka, Jussi Paanajärvi \\ Microsoft \\ Espoo, Finland \\ petteri.alinikula@microsoft.com
}

\begin{abstract}
Mobile technology offers great opportunities for renewing corporations' sustainability agenda. In particular, the positive impact can be increased and new segments of people can be engaged. Gaming for Good is an area that combines the most popular mobile applications, games, with sustainability ingredients. In particular three different elements of sustainability can be introduced: education, profit for purpose and new communication channel. Modern Mayor is a recently launched free-to-play casual strategy game that includes pioneering features for environmental education, in-application charity donations and integrated twitter account for bidirectional communication The start of the game shows promise for making Gaming for Good a permanent part of corporate sustainability.
\end{abstract}

Index Terms-Sustainability, mobile applications, mobile games, gaming for good.

\section{INTRODUCTION}

Sustainable development has become an integral part of the agenda of responsible corporations. Typically the agenda, in particular for the product companies, focuses on energy and resource efficiency improvements. For some companies the environmental agenda is complemented by social projects. Social projects can consist of charity donations to nongovernmental organizations (NGO) that reflect the values and priorities of the corporation. Some corporations, such as Nokia, have selected to conduct their social agenda by utilizing their own technology for the benefit of the people in need. Nokia has, for example, developed education services optimized for affordable mobile phones [1].

There are, however, some key challenges with social initiatives. Firstly, the impact of social projects is very difficult to measure. Then, prioritization of different opportunity areas becomes extremely difficult. Additionally, most social projects in corporate context are not self-sustaining and difficult to scale.

Lately, mobile applications have shown to offer extremely cost efficient global distribution channel for different types of digital content. The applications that people spend by far the most time with are games. The rankings of the most used and most grossing applications in all mobile application stores are all the time topped by games. In sustainable area the selection of Games for Good has been limited. One of the pioneering games was Climate Mission that Nokia introduced for various mobile platforms [2]. The game is about global warming and the player tries to mitigate the climate change.

The objective of this paper is to discuss the opportunities that Gaming for Good has for renewing sustainability agendas for corporations. In particular, the key opportunitiesedutainment, value creation through in-application donations, and a new communication channel-are discussed. Finally, a new Game for Good, Modern Mayor, is presented. Modern Mayor is a pioneering game providing profit for purpose and a new communication channel based on integrated social media.

\section{EDUTAINMENT}

The most straightforward means of bringing the social element into a game is to design it to be educational, i.e., the player learns by playing the game. Edutainment games refer to games where there is an obvious educational aspect included. Climate Mission is a typical example of the edutainment game: the player learns about the climate change and ways of mitigating that while playing. Edutainment and gamification in education has been studied extensively [3]. Studies have shown that gamification accelerates the learning process significantly. It is, however, vital that the educational element does not compromise the gaming experience for the edutainment games but brings an added do-good excitement.

\section{VALUE CREATION FROM GAMING FOR GOOD}

Social projects in corporate context are seldom selfsustaining. Often the activities are funded from corporation's budget; then, the projects are successful only until the funding dries out. The more lasting impact can be gained when the business model is designed so that the activity is selfsustaining. Business models and value creation from sustainability are discussed in [4] and [5]. According to [4] activities can be analyzed with the help of the diagram shown in Figure 1. The sweet spot of activities is in the top right corner of the diagram. These activities bring good profit but also provide high impact to sustainability; they should be implemented even without the sustainability impact. 


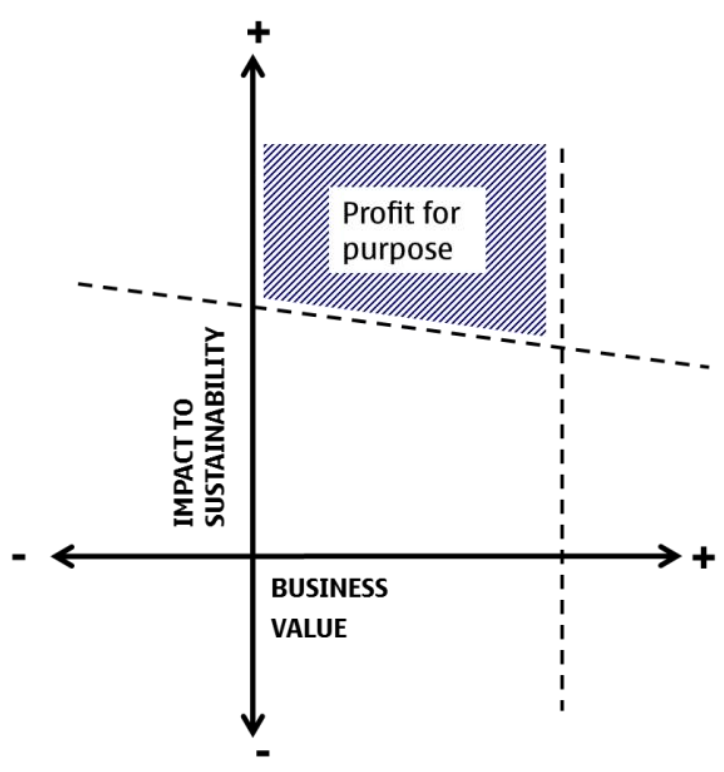

Fig. 1. Profit for purpose value creation

For sustainability activities corporations can typically tolerate lower or even negative profitability when the impact to sustainability is high enough. This sustainable development area extends in the upper part of the diagram. The area where sustainable value is high but the activity is still profitable is the Profit for Purpose. Profit for Purpose offers opportunity-but does not guarantee-economical sustainability of corporations' social activities.

For mobile games the most profitable monetization model lately has been free-to-play gaming with so-called in-app purchases. In-app purchases are micropayments that are not mandatory for playing the game but can be used for accelerating the progress of the game. In-app purchases offer a great opportunity for Profit for Purpose: major part of the collected in-app purchases can be donated to selected charity projects while guaranteeing core funding for the maintenance and future updates of the game. NGOs can be used for offering suitable funding projects for the game.

\section{COMMUNICATION CHANNEL}

Communication and storytelling are important elements in sustainability. The impact of the good sustainability activities is multiplied when stories are shared and good practices expand to new organizations and markets. The key challenge is to reach people's attention in the presence of continuous information overflow. Mobile gaming is unique in that sense that when a person plays the game the full attention has already been captured. Then, mobile games can be used as a new communication channel by integrating social media into the game. New segment of people is reached and the communication becomes transparent and two-directional. Accordingly, integrated social media serves as a direct feedback channel to corporations. It is, however, vital that the social media channel is used selectively and not loaded with annoying information.

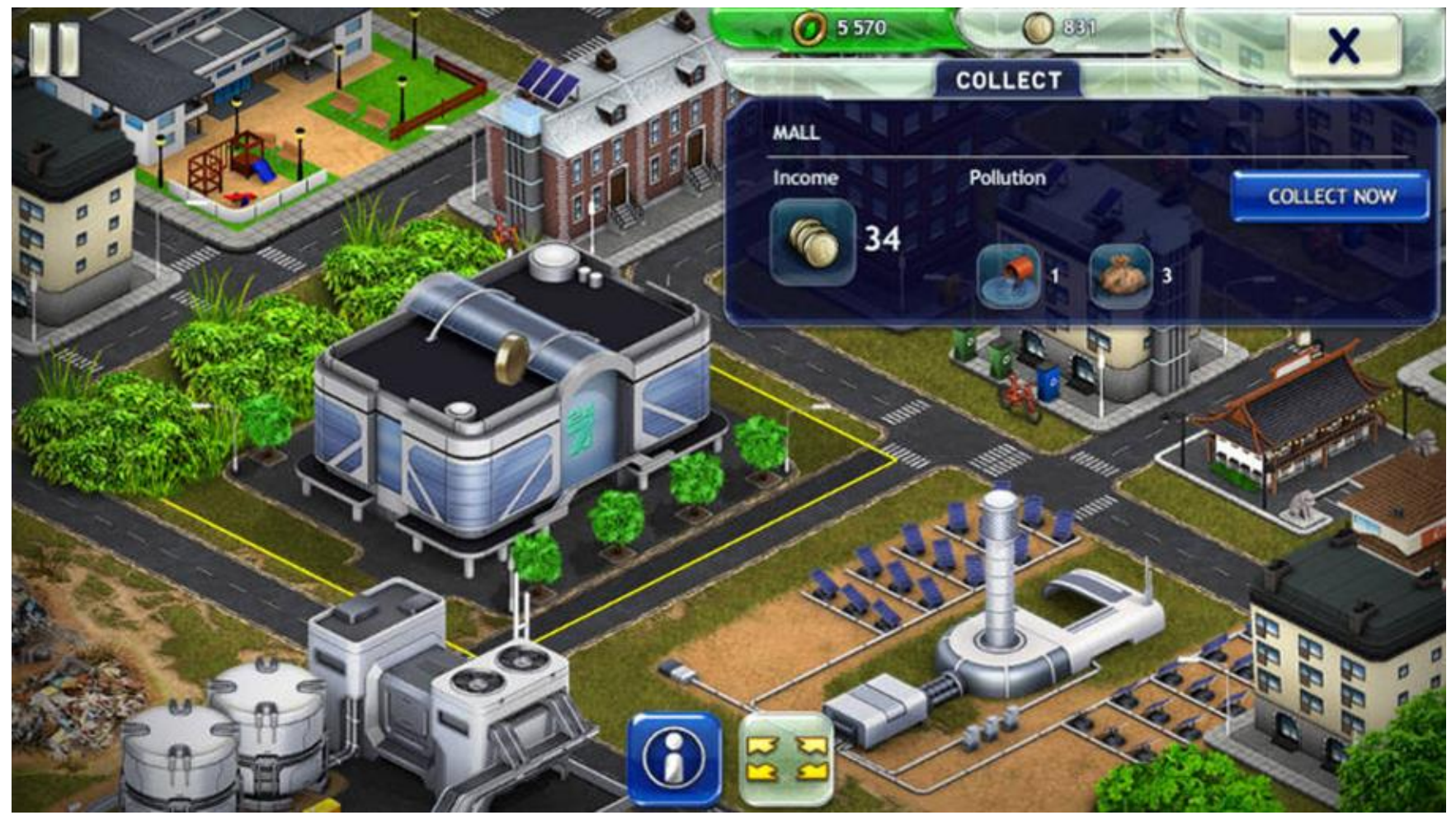

Fig. 2. City building in Modern Mayor 


\section{MODERN MAYOR}

Modern Mayor is a pioneering Game for Good that was launched globally in Windows Phone Store in late February 2014 [6]. The target was to create a best-of-a-class game that people would be excited to play and then innovate the do-good angle to the game. Gaming for Good with Modern Mayor was designed not to compromise the gaming experience but bring new ingredients to the game. Modern Mayor is a free-to-play casual strategy game. The player is employed as a mayor of a rotten city and by completing environmental improvement missions the city gets cleaner and the player advances to new levels. An example screen shot of the game illustrating an advanced city is shown in Figure 2.

The sustainability aspect is brought into Modern Mayor through three different means. Firstly, the topic of the game, cleaning and making the city more environmentally friendly, provides education regarding sustainable development and environmental actions. Secondly, while the game is free to play, the player can advance faster in the game using in-app purchases. The key innovation in Modern Mayor is that the funds received are used for charity with the partnering NGOs. In the first phase the NGO partners in the game are WWF and OXFAM $^{1}$. The progress for the charity projects can be followed inside the game. The business model is Profit for Purpose: part of the funds is directed to the maintenance and further development of the game but the vast majority is handed to the charity projects.

In Modern Mayor the communication officer of the townhouse, Townhall Laura, tweets on important topics happening in the game and elsewhere. Similarly, the gamers can tweet on any topics that they find important. Townhall Laura can develop into a lively discussion forum on any timely issues.

At the moment of writing this paper Modern Mayor has been globally available for two weeks. While it is very early to judge the success of the game the start is very promising. During the first week the game was downloaded about 50000 times with a very healthy number of more than 10000 active daily users. Furthermore, the in-app purchases have been used actively with all charity projects progressing steadily and gaining speed. Townhall Laura's twitter account has been picked up by about 300 followers during the first week.

\section{CONCLUSION}

Mobile technology offers great opportunities for renewing corporations' sustainability agenda. In particular, the positive impact can be increased and new segments of people can be engaged. Gaming for Good combines the most popular mobile applications, games, with sustainability ingredients. In particular three different elements of sustainability can be introduced: education, profit for purpose and new communication channel. Modern Mayor is a recently launched free-to-play casual strategy game that includes pioneering features for environmental education, in-application charity donations and integrated twitter account for bi-directional communication The start of the game shows promise for making Gaming for Good a permanent part of corporate sustainability.

\section{ACKNOWLEDGMENT}

The authors would like to thank Kuuasema ${ }^{2}$ and its talented team for developing Modern Mayor, the greatest Game for Good.

\section{REFERENCES}

[1] www.nokia.com/global/about-nokia/people-and-planet-page

[2] www.nokia.com/global/about-nokia/people-andplanet/sustainable-devices/apps/apps-and-services/

[3] J.P Gee, What Video Games Have to Teach Us About Learning and Literacy. Palgrave Macmillan, 2003.

[4] P. Alinikula, "Sustainability as an Innovation Catalyst for Mobile Phones," Digest $24^{\text {th }}$ ISPIM Conf. Finland, 2013.

[5] M. Halme and E. Laurila, "Philanthropy, integration or innovation? Exploring the financial and societal outcomes of different types of corporate responsibility," Journal of Business Ethics, 84, pp.325-339, 2009.

[6] forum.modernmayor.com

1 www.wwf.org and www.oxfam.org

2 www.kuuasema.com 